\title{
Cloning, Sequencing and Production of Recombinant Polyclonal Antibodies against Egyptian Staphylococcal Enterotoxin A
}

\author{
H. A. Nour El-Din ${ }^{1, *}$, M. N. Abu El-Naga ${ }^{2}$, M. E. El-Fouly ${ }^{2}$, M. K. Ibrahim ${ }^{3}$, E. H. El-Shatoury ${ }^{3}$, H. A. Hussein ${ }^{2}$ \\ ${ }^{1}$ Agricultural Genetic Engineering Research Institute (AGERI) \\ ${ }^{2}$ National Center for Radiation Research and Technology, Atomic Energy Authority, Cairo, Egypt \\ ${ }^{3}$ Faculty of Science, Ain Shams University \\ *Corresponding author: hanannour53@hotmail.com
}

\begin{abstract}
Staphylococcus aureus (S.aureus) is the most common pathogen found in hospitals, community-acquired infections and colonizes up to 50\% of humans, including mucous membranes and damaged skin. Some strains produce enterotoxins (Ent) as staphylococcal enterotoxin A (SEA) which is involved in $75 \%$ of food poisoning outbreaks. Few methods are sensitive and specific enough to confirm the diagnosis of staphylococcal food poisoning. In this study, a segment of Ent A-ORF with molecular weight 774 bp was amplified, cloned, sequenced and aligned with published Ent A-ORFs. Ent A-ORF was subcloned into bacterial expression vector (GST-PGEX4T1 vector) and expressed as a fusion protein with GST-tagged protein. A band size of $27 \mathrm{kDa}$ of purified Ent A protein was cleaved from GST protein by thrombin. The expressed protein of Ent A was identified by strong reaction with commercialized polyclonal antibodies against Ent A. Antiserum against Egyptian recombinant Ent A protein was produced by immunization of Balb/c mice, the produced recombinant polyclonal antibodies had a titre of 1:2500 in direct ELISA. The produced recombinant polyclonal antibody was evaluated and reacted specifically in Western immunoblotting analysis and ELISA test. Finally from the obtained results, the produced recombinant protein of Ent A can be used successfully for production of recombinant polyclonal antibodies and used in large-scale detection of staphylococcal enterotoxin A.
\end{abstract}

Keywords: staphylococcus aureus, Ent A, cloning and expression, ELISA, polyclonal antibody

Cite This Article: H. A. Nour El-Din, M. N. Abu El-Naga, M. E. El-Fouly, M. K. Ibrahim, E. H. El-Shatoury, and H. A. Hussein, "Cloning, Sequencing and Production of Recombinant Polyclonal Antibodies against Egyptian Staphylococcal Enterotoxin A." American Journal of Microbiological Research, vol. 5, no. 6 (2017): 131-137. doi: 10.12691/ajmr-5-6-3.

\section{Introduction}

Staphylococcal enterotoxins (SEs) are the second most common causal agents of food poisoning and clinical infections throughout the world [1,2]. Therefore, its paramount importance to use quick, accurate and sensitive methods for detecting them. For developing of an effective immunodetection system, availability of sensitive and specific antibodies against SEs is the major bottleneck.

There are over 30 species of identified staphylococci, and they are typically found on the skin and mucous membranes of mammals. About a dozen species are frequently carried on humans, including Staphylococcus aureus, S. epidermidis, S. haemolyticus, S. capitis, S. hominis, S. cohnii, S. lugdunensis, S. schleiferi, S. saprophyticus, S. simulans, S. warneri and S. xylosus. All these species are capable of causing disease in humans, but $S$. aureus is by far the most aggressive pathogen and is the species most commonly implicated in food poisoning [3]. Therefore, this work focused on enterotoxin A from $S$. aureus.
S. aureus are differentiated from other staphylococci in the diagnostic laboratory by their ability to coagulate plasma. S. aureus also encode and produce a wide range of toxins, immune escape mechanisms and other virulence factors and are becoming increasingly resistant to antibiotics. They are a major cause of hospital-acquired infection and an increasing cause of veterinary infection and are a common cause of mastitis in dairy cows. It is also a common cause of food poisoning, due to bacterial staphylococcal enterotoxins (SEs) that are heat resistant. Because symptoms usually resolve within 24 hours without treatment, it is likely that most cases remain undiagnosed or unreported. Carriage of SE genes varies widely between $S$. aureus strains, and some enterotoxins are more commonly associated with food poisoning than others [4].

Enterotoxins are a very common cause of food poisoning; S. aureus is so ubiquitous that food storage and handling must be carefully controlled to prevent $S$. aureus growth and toxin production. A wide range of SE toxins are produced by $S$. aureus that are capable of causing vomiting, and each is distributed amongst $S$. aureus strains differently, they regulated differently and can transfer between strains on different types of genetic 
elements. The robustness of the organism permits its growth in many types of food, producing enterotoxins subsequently causing food poisoning. The bacteria can be killed through heat treatment of the food, but the enterotoxins are very heat resistant. Thus, although the bacteria are eliminated, the toxins will remain and can cause food poisoning [5].

Detection methods of enterotoxins are not very sensitive, and live $S$. aureus are not necessarily found in contaminated food, but improved methods are being developed [6]. In the future, new toxins may be discovered, detection methods should become more sensitive and hopefully more may become known about factors that control $S$. aureus spread and toxin production in food.

In this study, we produced of Egyptian staphylococcal enterotoxin A protein as a purified recombinant toxin and used it as an antigen to produce polyclonal antibodies for developing a sensitive and reliable diagnostic ELISA kit for Ent A detection.

\section{Materials and Methods}

\subsection{Amplification of Ent A Gene}

The bacterial DNAs were extracted from the positive control (S.aureus strain ATCC number 9128 was used as reference strain) and positive tested sample SA 41 (sample 41 was published in [7] that were used as a template in PCR) and the two specific primers for Ent $A$ gene as follows:

Ent A-F:

5'CGGGATCCATGAAAAAAACAGCATTTACA'3 Ent A-R:

5'CCGCTCGAGTTAACTTGTATATAAATATATAT'3.

The bold letters represent Bam $\mathrm{H} 1$ and Xhol restriction sites in the Ent A-Forward (Ent A-F) and Ent A-Reverse (Ent A-R), respectively. Ent A-F and Ent A-R were designed based on the published Ent A sequence of [8]. All used primers were synthesized by Biosearch Technologies (US \& Canada).

PCR was conducted in a volume of $50 \mu \mathrm{l}$ containing, $1 \mathrm{X}$ reaction buffer with $\mathrm{MgSO} 4,200 \mu \mathrm{M}$ each dNTPs (dATP, dTTP, dCTP and dGTP), 0.4 pmol of each primer, 0.025 units of Pfu DNA polymerase, template and d.d. $\mathrm{H}_{2} \mathrm{O}$. PCR was performed in a Perkin-Elmer (Gene Amp PCR System 2400) for 35 cycles after initial denaturation for $10 \mathrm{~min}$ at $95^{\circ} \mathrm{C}$. Each cycle consisted of denaturation at $95^{\circ} \mathrm{C}$ for $35 \mathrm{sec}$, annealing at $55^{\circ} \mathrm{C}$ for $1 \mathrm{~min}$, extinsion at $72^{\circ} \mathrm{C}$ for $1 \mathrm{~min}$. The primer extension was extended to $7 \mathrm{~min}$ at $72^{\circ} \mathrm{C}$ in the final cycle. Amplified fragment of the Ent $A$ gene separated using $1.2 \%(\mathrm{w} / \mathrm{v})$ agarose gel electrophoresis. The PCR amplified product was detected by electrophoresing on $1.2 \%$ agarose gel in $1 \mathrm{X}$ TAE buffer at 80 volts for one hour [9].

\subsection{Cloning of Ent A gene in pGEM-T Easy Vector}

Post PCR amplification, $25 \mu \mathrm{l}$ from the PCR product was heated at $95^{\circ} \mathrm{C}$ for $20 \mathrm{~min}, 7.5 \mu \mathrm{dATP}$ (from a $2 \mathrm{mM}$ stock), $1.5 \mu \mathrm{MgCl}_{2}$ (from a stock $50 \mathrm{mM}$ ) and $1 \mu \mathrm{l}$ (0.5 Unit) of Taq DNA polymerase were added, and the mixture was incubated at $70^{\circ} \mathrm{C}$ for $15 \mathrm{~min}$. Wizard $\AA$ DNA Clean-Up System kit (Thermo Scientific \#K0691) was used to purify the PCR product after A-tailing. A-tailed PCR fragment was ligated into the pGEM-T easy vector in a volume of $20 \mu \mathrm{l}$. Competent cells of E. coli (strain JM 109) were prepared using $\mathrm{CaCl} 2$ as described by [10]. The method of transformation was carried out as described by [11]. The Wizard $\AA$ plasmid mini-preparation system from Promega was used to isolate pure super-coiled plasmid DNA with high yields. The PCR product was cloned into pGEM-T Easy vector to create the plasmid pNH1(pGEM$\mathrm{T}$ easy vector + Ent $\mathrm{A}-\mathrm{ORF}$ ) that introduced into $E$. coli strain $\mathrm{GC}_{5}$. After mini-preparation, the purified plasmid DNA was subjected to digestion with the restriction endonucleases BamHI and XhoI and PCR detection.

\subsection{Sequence Analysis}

fter confirmation, DNA of a recombinant clone $\mathrm{pNH} 1$ was sequenced using F and R T7 pGEM universal primers (Eurofins Scientific, Germany).

The NCBI online BLAST tool was used to align the generated sequences using BLAST algorithm [12] against the NCBI database. PERL scripts were used to visualize BLAST results using Circos software package (Circos 0.66) [13]. Multiple Sequence Alignment using T-Coffee. Multiple Sequence Alignment online Tools was used to obain Percent Identity Matrix Alignment (http://www.tcoffee.org/Projects/tcoffee/).

Protein structure homology modeling has become a routine technique to generate 3D models for proteins. SWISS-MODEL and Phyre $^{2}$ were used in this study for protein modeling and structure. SWISS-MODEL (http://swissmodel. expasy.org/) is an automated system for modeling the 3D structure of a protein from its amino acid sequence using homology modeling techniques [14]. Each model built by Phyre2 is based on an alignment generated by HMM-HMM matching [15].

\subsection{Expression of Ent A Gene Using PGEX System}

A according to the manual instructions of GST Gene Fusion System Handbook (GE Healthcare life Science), the sequenced clone was digested with BamHI and XhoI restriction endonuclease enzymes and the released fragment was subcloned into PGEX4T1 vector that was previously digested with the same restriction enzymes, and the obtained plasmid designated $\mathrm{pNH} 2$. After ligation, plasmid was transformed into E.coli strain BL21. The recombinant plasmid was screened under two different concentrations from IPTG (1 and $0.1 \mathrm{mM})$ at different incubation times $(1,2,3 \mathrm{hr}$ and overnight respectively at $37^{\circ} \mathrm{C}$ and $\left.16^{\circ} \mathrm{C}\right)$. The protein(s) was determined using $12 \%$ SDS-PAGE.

\subsection{Detection of Expressed Ent A Protein Using Western Blotting Analysis}

In this experiment, western blot technique was used as described by [16]. The total proteins were extracted from transformed and non-transformed $E$. coli, electrophoresed on $12 \%$ SDS-PAGE and blotted onto membrane ((Immobilon 
( $\mathrm{B}$ PVDF membrane, Millipore cooperation, Bed ford, MA 01730) using a trans-blot apparatus (Bio-Rad). After blocking with $5 \%$ bovine serum albumin, the membrane was treated with appropriate dilutions enterotoxin A antibody as primary antibody (commercialized polyclonal antibodies against Ent A, product No.S7656, USA). Membrane was washed with TBS-T/Triton buffer and then alkaline phosphatase (ALP)-conjugate (goat anti-rabbit IgG Sigma Cat\# A-3562) was added in a dilution of 1:30000 (in conjugate buffer) to the membranes and incubated for $1 \mathrm{hr}$ at RT with gently shaking. After washing the color reaction was started by incubating the membranes in BCIP/NPT in substrate buffer and the membrane was left until the desired bands appeared. The reaction was stopped by washing the membranes with double d. $\mathrm{H}_{2} \mathrm{O}$ (d.d. $\mathrm{H}_{2} \mathrm{O}$ ) for several times. The membrane was air dried on a filter paper and photographed.

\subsection{Production and Purification of the GST- Tagged Fusion Protein}

After expression and confirmation process, the purification steps was carried out in large scale by using GST bulk kit (from GE-Healthcare Bio-science AB \# cat. No. 27457001) and finally analyzed by SDS-PAGE [9].

According to the manual instructions of GST Gene Fusion System Handbook (GE Healthcare life Science), the recombinant protein of Ent A was separated from GST protein by Thrombin enzyme. Total protein was determined using Pierce ${ }^{\mathrm{TM}}$ BCA Protein Assay Kit (Thermo fisher Cat \# 23225) with BSA as standard for quantizations of the total protein.

\subsection{Production of Polyclonal Antibody}

Antiserum was raised against expressed Ent A protein by injecting two balb/c mice with the purified Ent A protein. The sequence of doses was 10,10 , and $5 \mu \mathrm{g}$ recombinant SEA [17]. Ent A were emulsified with an equal volume of freund's complete adjuvant and injected Intraperitoneal for the first and incomplete adjuvents for the second two subsequent intramuscular injections at weekly intervals. After immunizations, the immune responses of the mice were measured by indirect ELISA. The blood was collected at weekly intervals 4 weeks post of the first injection followed by incubation at $37^{\circ} \mathrm{C}$ for 1 $\mathrm{h}$ and low centrifugation $(4000 \mathrm{rpm})$ at RT. The antiserum was collected and stored at $4^{\circ} \mathrm{C}$ until required. The IgGs concentration was then adjusted to $1 \mathrm{mg} / \mathrm{ml}(\mathrm{A} 280 \mathrm{~nm}=$ 1.46, Clark and Adams, 1977) and stored at $-20^{\circ} \mathrm{C}$ until required. IgGs were conjugated with ALP according to the protocol given by $[18,19]$. The double antibody sandwich (DAS)-ELISA [20,21] was used to determine titer of antiserum.

\subsection{Determination the Specificity and Sensitivity of the Produced Antibodies}

The specificity and sensitivity of the produced IgGs against recombinant Ent A protein were determined by western blotting as described by [16] using the produced recombinant IgGs as a polyclonal antibodies.

\section{Results}

\subsection{PCR Amplification of Ent A Gene}

The bacterial DNAs from the positive control and positive ELISA tested sample (sample 41) were used as a template in PCR and the amplified interested gene was $774 \mathrm{bp}$ and were detected in both samples (Figure 1).

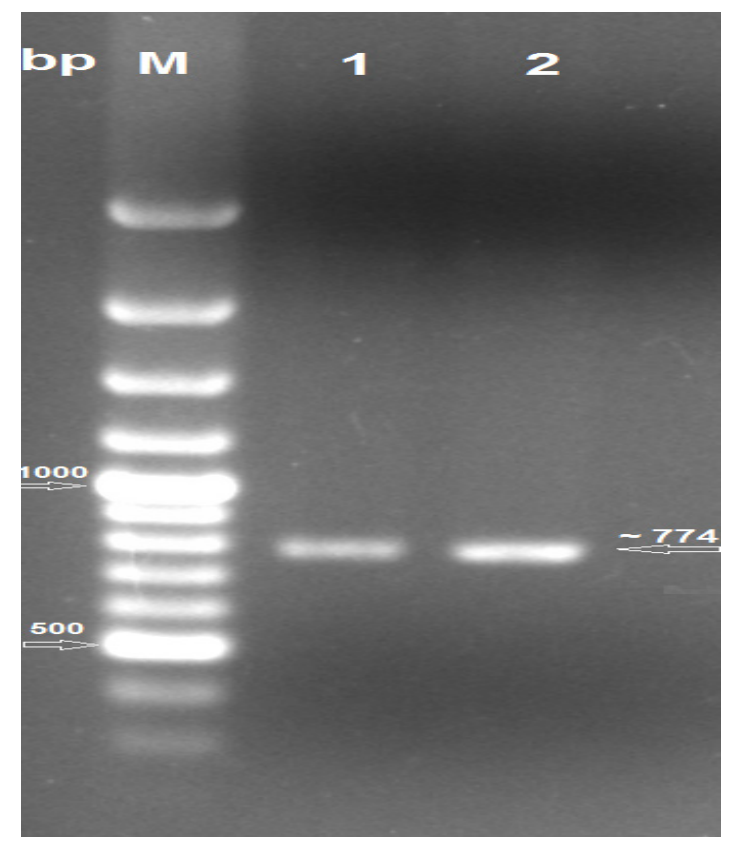

Figure 1. Agarose gel electrophoresis showing PCR amplification of Ent A gene. M: 100 bp DNA marker, 1: PCR amplification using DNA from reference strain and 2: PCR amplification using DNA from sample-41

\subsection{Cloning of Ent A Gene}

The dsDNA PCR product was cloned into pGEM-T Easy vector to create the plasmid and putative clone was designated pNH1 (Figure 2) that was transformed into E. coli strain $\mathrm{GC}_{5}$.

After mini-preparation, the purified plasmid DNAs were subjected to digestion with $B a m \mathrm{HI}$ and $\mathrm{XhoI}$ as a confirmatory test, a segment of about 774 bp (Figure 3) were released from all recombinant plasmids.

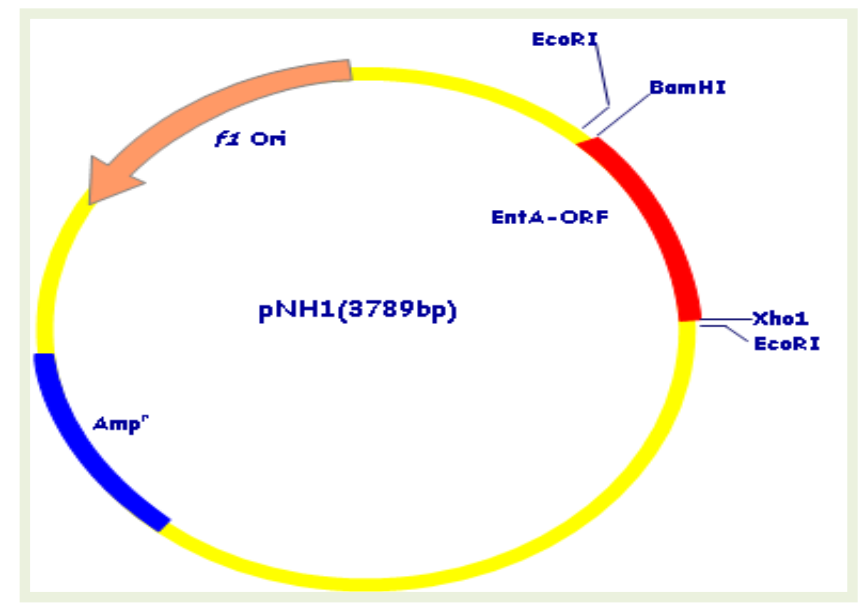

Figure 2. A diagram showing plasmid pNH1 (pGEM-T easy vector $+E n t$ A-ORF) 


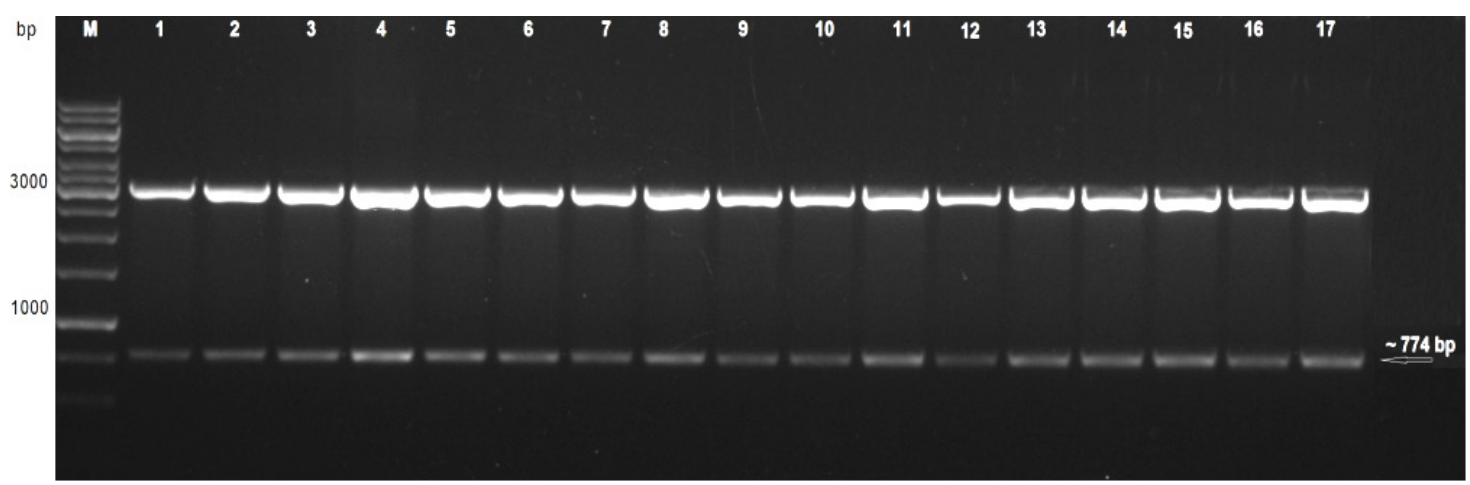

Figure 3. Digestion reaction of recombinant plasmids with BamHI \& Xho1. M: 1Kb DNA marker. Lanes: from 1 to 9 represent the released fragments from the recombinant plasmids extracted from reference strain. Lanes 10 to 17 represented recombinant plasmids of SA-41 strain

\subsection{Sequence Analysis and Alignment}

After confirmation, DNA of a recombinant clone $\mathrm{pNH} 1$ was sequenced. In Figure 4, the nucleotide sequences of Ent $A$ gene of Egyptian isolate of staphylococcus aureus was 774bp nucleotides with one open reading frame (Accession No. NAGAH1 KX777250).
Depending upon the resulted sequencing data of SA-41 isolate, these readings were aligned with NCBI Basic Local Alignment Search Tools (BLASTs). The Ent A of the Egyptian isolate (SA-41) gave a high sequence similarities with Ent A genes belonging to different isolates of $S$. aureus and the similarities were ranged $91-100 \%$ based on nucleotide sequences (Figure 5).

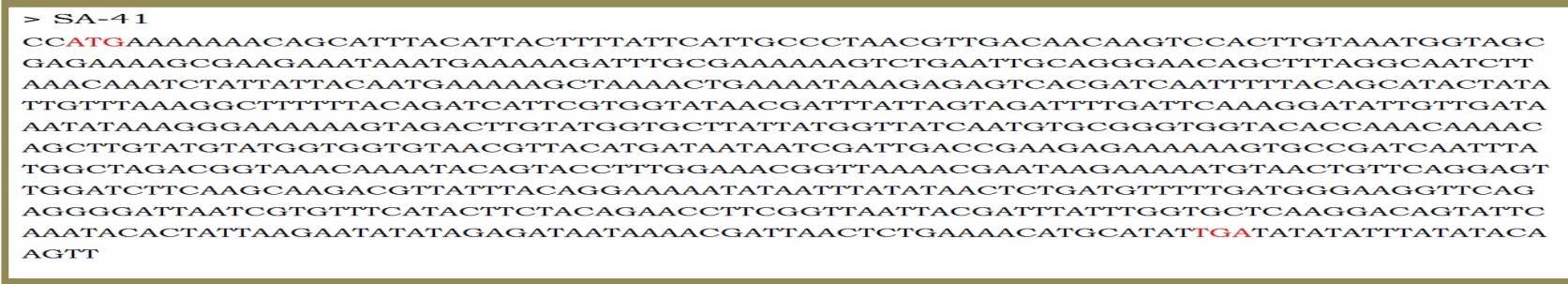

Figure 4. DNA nucleotide sequences of Ent A gene of SA-41, red labelled sequence clarified both start and stop codons

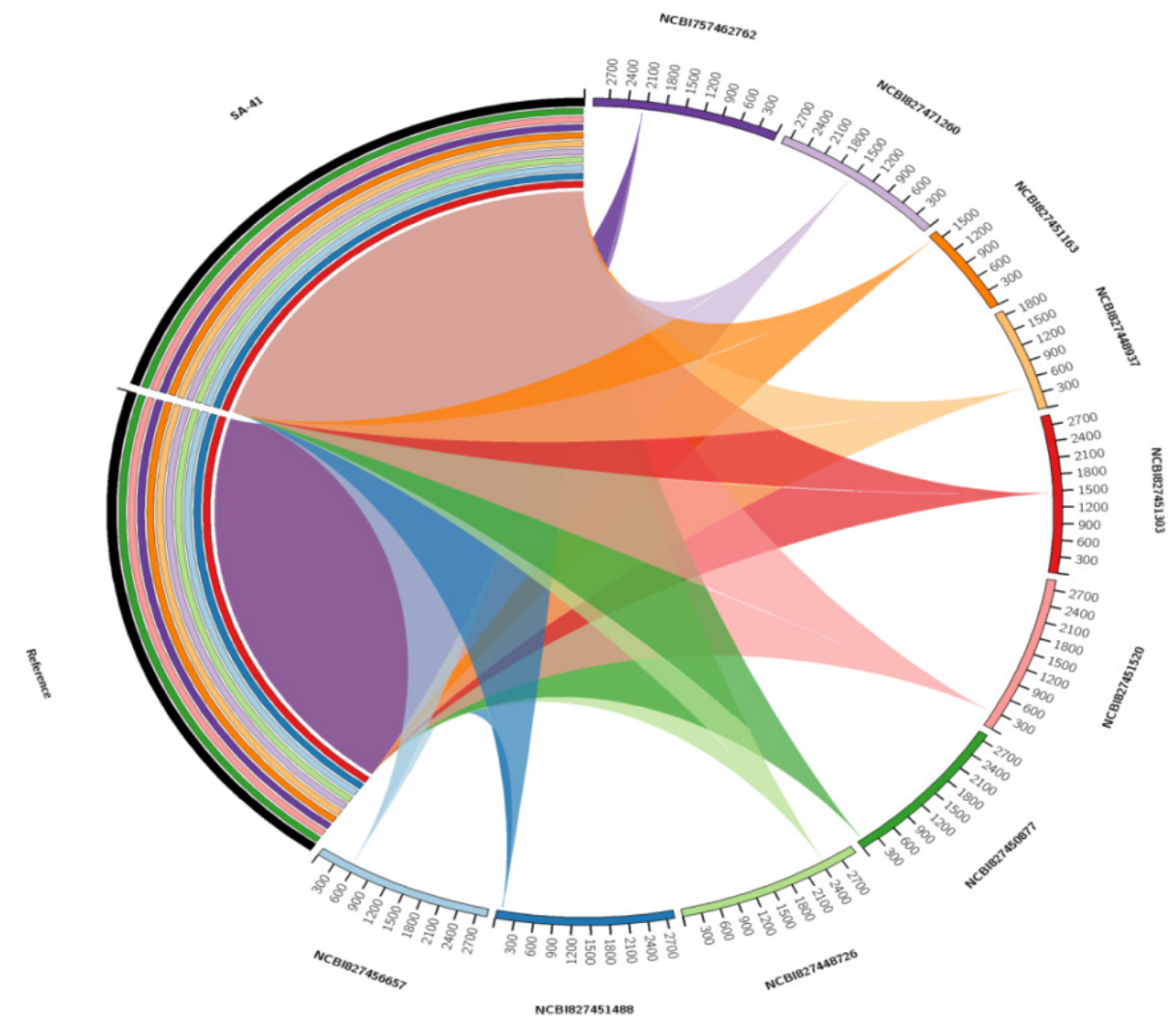

Figure 5. Sequence similarity alignment of Ent A-ORF for SA-41 in comparing with the NCBI database using Circos software package (Circos 0.66) along all the bacterial species. The black track indicates bars of SA-41 774. bp. The height of each bar illustrates the total number of bases of the opposite genome aligned to this $774 \mathrm{bp}$ region 


\subsection{Expression and Purification of Ent A Gene}

The sequenced clone was digested with BamHI and Xho1 restriction endonuclease enzymes and the released fragment was subcloned into PGEX4T1 vector that was previously digested with the same restriction enzymes, and the obtained plasmid designated pNH2 (Figure 6).

The plasmid pNH2 was transformed into E.coli BL 21 and was induced by adding IPTG. The best condition for Ent A protein expression was $0.1 \mathrm{mM}$ IPTG at $16^{\circ} \mathrm{C}$ for overnight incubation. The expressed protein was $53 \mathrm{KDa}$ (26 KDa represents GST tagged protein and $27 \mathrm{KDa}$ represent Ent A recombinant protein).

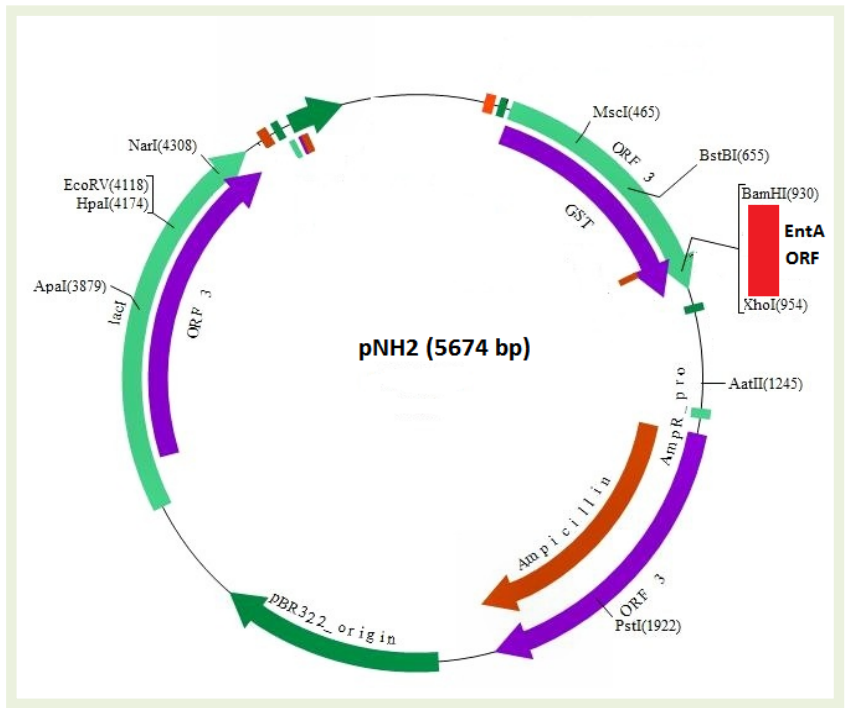

Figure 6. $\mathrm{pNH} 2$ recombinant plasmid diagram (PGEX4T1 vector + Ent $A$ gene)

The Ent A recombinant protein for both reference strain and SA-41 strain were purified by GST purification protocol. SDS-PAGE revealed a purified expressed protein at $53 \mathrm{KDa}$ (Figure 7).

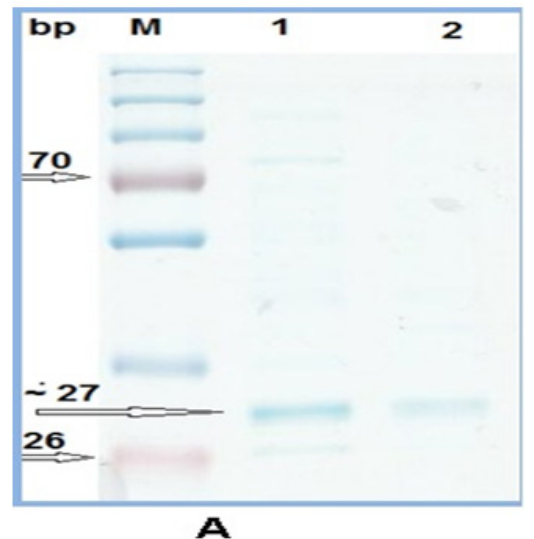

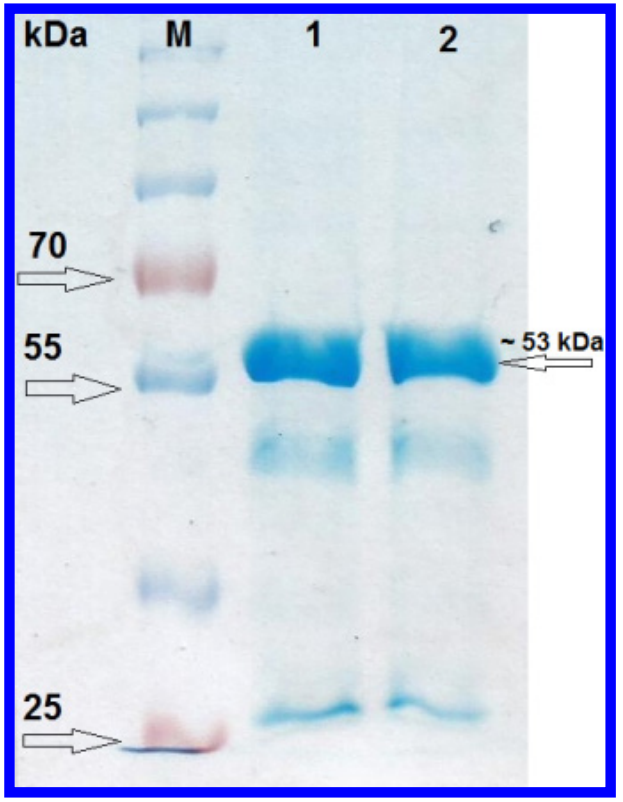

Figure 7. Purification of fusion GST-Ent A fusion protein. M: represents standard protein marker (Biolabs). Lane 1: Purified fusion protein of positive sample. Lane 2: Purified fusion protein of sample 41

\subsection{Detection the Specificity of Fusion Protein}

In Figure $8 \mathrm{~A}$, the fusion protein $(53 \mathrm{KDa})$ was digested with Thrombine enzyme to separate GST tagged protein $(26 \mathrm{KDa})$ from expressed Ent A protein $(27 \mathrm{KDa})$.

The specificity of the produced expressed fusion protein was determined by Western blotting analysis (Figure 8B). The commercialized polyclonal antibodies against Ent A was reacted strongly and specifically with $27 \mathrm{KDa}$ protein band in both samples (reference and sample 41). This result indicated that the produced recombinant protein of Ent A can be used successfully in production of polyclonal antibodies with high specificity and sensitivity.

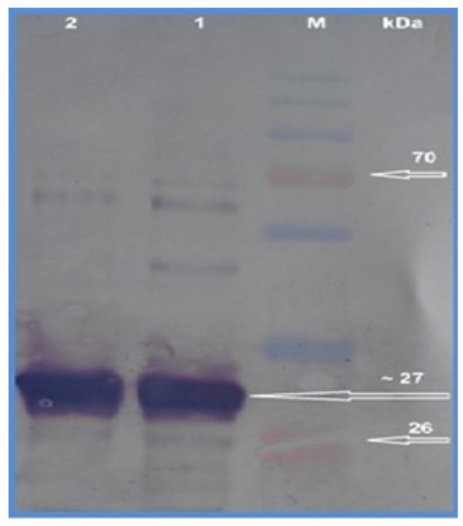

B

Figure 8. A: SDS-PAGE of standard strain and 41 sample after removed the GST tagged protein from both recombinant proteins. B: Western blotting analysis probed both recombinant proteins with the commercialized polyclonal antibody. M: Standard protein marker. Lanes 1: represents the standard sample. Lane 2: represents sample 41

\subsection{Polyclonal Antibody Production against Recombinant Protein Ent A}

After protein expression, purification and cleavage procedures, the yield of recombinant Ent A protein was
$0.5 \mathrm{mg} / 100 \mathrm{ml}$ of culture medium. Antiserum was raised against Ent A protein, and the produced polyclonal antibodies was purified and IgGs concentration was determined by ELISA and adjusted to $1 \mathrm{mg} / \mathrm{ml}$. Following that, IgGs were conjugated with the Alkaline phosphatase. DAS-ELISA 
results revealed that the titer of $\operatorname{IgG}$ was 1:2500. The titer was calculated according to the signal in ELISA with Ent
A which should be at least 2 fold higher than the signal produced with negative Ent A producing isolates (Table 1).

Table 1. DAS-ELISA for determination the titer of the produced IgGs against ent A protein

\begin{tabular}{|c|c|c|c|c|c|c|c|c|c|c|c|c|}
\hline \multirow{3}{*}{ Samples } & \multicolumn{12}{|c|}{ IgG titer } \\
\hline & \multicolumn{2}{|c|}{$1 / 500$} & \multicolumn{2}{|c|}{$1 / 1000$} & \multicolumn{2}{|c|}{$1 / 1500$} & \multicolumn{2}{|c|}{$1 / 2000$} & \multicolumn{2}{|c|}{$1 / 2500$} & \multicolumn{2}{|c|}{$1 / 3000$} \\
\hline & EV & $\mathbf{R}$ & $\mathbf{E V}$ & $\mathbf{R}$ & $\mathbf{E V}$ & $\mathbf{R}$ & $\mathbf{E V}$ & $\mathbf{R}$ & $\mathbf{E V}$ & $\mathbf{R}$ & $\mathbf{E V}$ & $\mathbf{R}$ \\
\hline Standard Ent A $(10 \mathrm{ug} / \mathrm{ml})$ & 4.09 & + & 3.37 & + & 2.76 & + & 2.82 & + & 1.84 & + & 0.72 & - \\
\hline Negative Ent A Isolate & 0.41 & - & 0.51 & - & 0.61 & - & 0.6 & - & 0.71 & - & 0.71 & - \\
\hline EV: ELISA values. & & $(+)$ : & itive. & & Negati & & & & & & & \\
\hline
\end{tabular}

\subsection{Determination of the Specificity and Sensitivity of the Produced Recombinant Polyclonal Antibody}

The sensitivity and specificity of the produced recombinant IgG was tested by Western blotting analysis using the protein extracts of $E$. coli strain BL21, pGEX4T1 vector (transformed in E. coli BL21) as negative control, positive control (Ent A protein), recombinant Ent A protein and crude extracts of culture of three Staphylococcus aureus local strains produce Ent A protein. Western blotting analysis revealed that the recombinant $\mathrm{IgG}$ reacted specifically with a protein of about $27 \mathrm{kDa}$ present in the induced culture of $E$. coli harbouring plasmid $\mathrm{pNH} 2$ and positive control. Moreover, the recombinant polyclonal antibodies also reacted specifically with the $27 \mathrm{kDa}$ of other Ent A produced from local strains as well as the purified fusion protein(s) (Figure 9 and Figure 10). This interested band seem to be absent in other extract of BL21 lysate and GST protein.

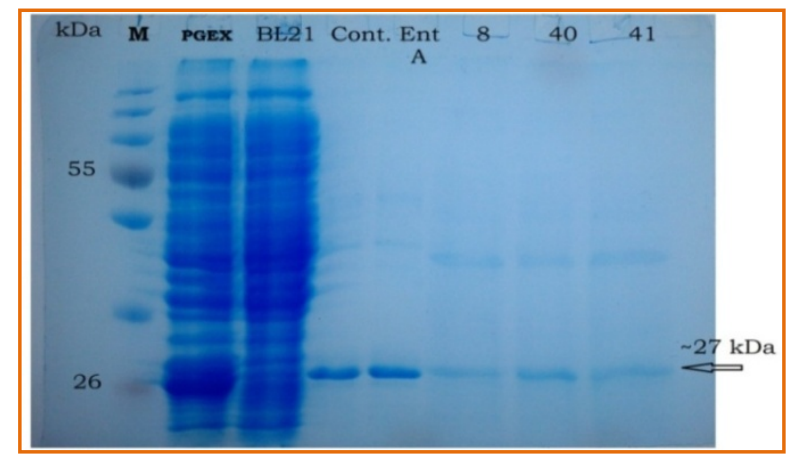

Figure 9. SDS-PAGE for Ent A protein whereas Lan1; protein ladder, lane 2; GST protein, lane 3; BL21 lysate as negative control, lane 4; positive control (Ent A protein), lane 5; expressed Ent A, lane (6-8); produced Ent A protein from three local strains (no 8, 40 and 41)

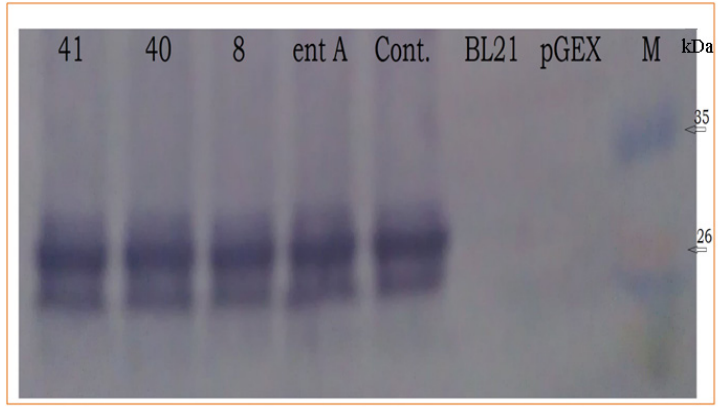

Figure 10. Western immunoblot of the produced polyclonal antibody in balb/c mic for Ent A protein.where as Lane1; protein ladder, lane 2; GST protein, lane 3; BL21 lysate as negative control, lane 4; positive control
(Ent A protein), lane 5; expressed ent A, lane (6 - 8); Ent A protein produced from three local strains (no 8, 40 and 41)

\section{Discussion}

The purpose of this study is to prepare antigenic recombinant protein of Ent $\mathrm{A}$ and used as an antigen for producing recombinant polyclonal antibody. In this study, PCR amplification for target Ent A gene was followed by sequencing to recognize length of interested gene and its nucleotide sequence, this experiment clarified that Ent A gene was $774 \mathrm{bp}$. This result is in harmony with [21] who found that coding sequence for Ent $\mathrm{A}$ is contained in an open reading frame of 774 base pairs and contained 258 codons, including the translation initiation and termination codons.

The BLAST analysis of the nucleotide sequence gave another good proof that the Ent A gene of Egyptian isolate SA-41 is belonging to Ent A genes.

Measuring of similarity matrix between strain SA-41 (Egyptian isolate) and published different isolates showed identity $99 \%$ and $100 \%$ for transcription level (amino acid sequence level) which indicated absence of mutation, but may be due to short genetic variations SNP (single nucleotide polymorphism) is possible. Similar results were reported by $[8,22]$.

After amplification, cloning and sequencing of Ent A gene, the Ent A gene was constructed to PGEX4T1 bacterial expression vector. The Ent A gene was expressed under the control of tac promoter which is induced by IPTG. It is worthy that the best condition for Ent A protein expression was $0.1 \mathrm{mM}$ IPTG at $16^{\circ} \mathrm{C}$ for overnight incubation. The expressed protein was analyzed by SDS-PAGE and the presence of a band with a molecular mass of approximately $53 \mathrm{KDa}$ (the expected size for the GST tagged protein $26 \mathrm{KDa}$ and Ent A recombinant protein $27 \mathrm{KDa}$ ). The recombinant protein of Ent A was separated from fusion partner GST tagged protein by using Thrombin enzyme.

After expression and purification of the recombinant protein, the concentration of purified recombinant protein was $0.5 \mathrm{mg} / 100 \mathrm{ml}$ of culture medium. The identity of the expressed fusion protein was confirmed by Western blotting analysis using commercialized polyclonal antibodies against Ent A, Western blot revealed a strong band at 27 KDa band of Ent A recombinant protein.

The expressed fusion protein of Ent A can be produced in large quantities and avoid the difficulties of staphylococcal growth and toxin production. It can be applied successfully for production of polyclonal antibodies free from any contaminant-derived immunogens. 
The recombinant polyclonal antibodies were produced against expressed protein of Ent A and DAS-ELISA test was used to determine an optimal concentration from IgG for the detection of Staphylococal Ent A. DAS-ELISA results revealed that the titer of IgG was 1:2500. ELISA method has proved their great worth in detection of $S$. aureus because it is rapid, inexpensive and does not require special skills.

The sensitivity and specificity of recombinant polyclonal antibody was tested by Western blotting analysis, the results were revealed that the produced IgG was reacted specifically with a protein of about $27 \mathrm{kDa}$ present in the induced culture of $E$. coli harbouring plasmid $\mathrm{pNH} 2$ and positive control. Moreover, the antiserum also reacted with Ent A protein produced from local strains as well as the purified fusion protein(s). This interested band seem to be absent in other extracts of BL21 lysate and GST.

Fusion protein technology has been applied to improve antigen expression in bacterial host and also to increase the quality of the produced polyclonal antibodies. The ability to express and purify the desired recombinant protein in a large quantity allows for its use in the development of Egyptian diagnostic kits and to limit importation from other countries. A availability of local diagnostic ELISA kit will facilitate testing large number of food samples, such as meat, milk and other food products, in food industries and agricultural Quarantine. This kit also will contribute in food safety program via improving the quality control of food production.

\section{Acknowledgments}

This work was supported financially by the Science and Technology Development Fund (STDF), Egypt, Grant No; 4405 .

\section{References}

[1] Agrawal, R., Singh, P.K., Sharma, S.K., Kamboj, D.V., Goel, A.K., \& Singh, L. (2012). "Highly Expressed Recombinant SEB for Antibody Production and Development of Immunodetection System," Indian J. Microbiol., 52(2): 191-196.

[2] Rasooly, R., Do, P., \& Hernlem., B. (2016). "Sensitive, Rapid, Quantitative and in Vitro Method for the Detection of Biologically Active Staphylococcal Enterotoxin Type E. Toxins," 8, 150.

[3] Wiedmann, M. \& Zhang, W. (2013). "Genomics of Foodborne Bacterial Pathogens," Springer New York Dordrecht Heidelberg London. ISBN 978-1-4419-7685-7.

[4] Pinchuk, I.V., Beswick, E.J. \& Reyes, V.E. (2010). "Staphylococcal enterotoxins," Toxins, (Basel), 2: 2177-2197.

[5] Le Loir Y, Baron F, Gautier M. (2003). "Staphylococcus aureus and food poisoning," Genet. Mol. Res, 2: 63-76.
[6] Rall, V.L.M., Sforcin, J.M., Augustini, V.C.M., Watanabe, M.T., Fernandes Jr., A., Rall, R., Silva, M.G., \& Araújo, Jr.J.P. (2010). "Detection of enterotoxin genes of Staphylococcus sp. Isolated from nasal cavities and hands of food handlers," Braz. J. Microbiol., 41: 59-65.

[7] Hussein, H.A., Ibrahim, M.K., Nour El-Din, H.A., El-Shatoury, E.H., El-Fouly, M. E., Abd-Eal, S.S. \& Abu El-Naga, M.N. (2016) "Molecular Screening of Staphylococcal Enterotoxin Type A Encoding Gene from MRS Clinical Isolates," American Journal of Microbiological Research, 4 (2): 68-72.

[8] Chen, L., Li, S., Wang, Z., Chang, R., Su, J. \& Han, B. (2012). "Protective effect of recombinant staphylococcal enterotoxin A entrapped in polylactic-co-glycolic acid microspheres against $S$. aureus infection," Veterinary Research, 43(1): 20. Available at: http://www.veterinaryresearch.org/content/43/1/20.

[9] Sambrook, J., Fritsch, E.F. \& Maniatis, T. (1989). "Molecular Cloning": A Laboratory Manual Cold Spring Harbor Laboratory, Cold Spring Harbor New York.

[10] Hammond, J. \& R. W. Hammond (1989). "Molecular cloning, sequencing and expression in Escherichia coli of the bean yellow mosaic virus coat protein gene. Journal of General Virology 70:1961-1974.

[11] Hanahan, D. \& M. Meselson (1983). "In Methods in Enzymology,' Vol. 100, Wu. et al. (eds), Acad. Press. NY, p. 333.

[12] Altschul, S.F., Boguski, M.S., Gish, W. \& Wootton, J.C. (1994). "Issues in searching molecular sequence databases," Nat Genet. $6(2): 119-29$.

[13] Krzywinski, M., Schein, J., Birol, I., Connors, J., Gascoyne, R., Horsman, D., Jones, S.J. and Marra, M.A. (2009). "Circos: an information aesthetic for comparative genomics," Genome Res., 19(9): 1639-45.

[14] Kelley, L.A. \& Sternberg, M.J E. (2009). Protein structure prediction on the web: a case study using the Phyre ${ }^{2}$ server," Journal of Nature Protocols, 4: 363-371.

[15] Marco, B., Bienert, S., Waterhouse, A., Arnold, K., Studer, G., Schmidt, T., Kiefer, F., Cassarino, T. G., Bertoni, M., Bordoli, L. \& Schwede, T. (2014). "SWISS-MODEL: modelling protein tertiary and quaternary structure using evolutionary information," Nucleic Acids Res., 42 (1): 252-258.

[16] Towbin H, Staehelin T, \& Gordon J. (1979). "Electrophoretic transfer of proteins from polyacrylamide gels to nitrocellulose sheets: procedure and some applications," Proc. Natl. Acad. Sci. USA, 76(9): 4350-4

[17] Kuang, H., Wang, W., Xu, L., Ma, W., Liu, L., Wang, L. \& Xu, C. (2013). "Monoclonal antibody-based sandwich ELISA for the detection of staphylococcal enterotoxin A," Int. J. Environ. Res. Public Health, 10:(4) 1598-608.

[18] Avrameas, S. (1969). "Coupling of enzymes to proteins with glutaraldehyde." Immunochemistry, 6: 43-52.

[19] Clark, M.F. \& A.N. Adams (1977). "Characteristics of the microplate method of enzyme-linked immunosorbent assay for the detection of plant viruses, " J. Gen. Virol., 34: 475-483.

[20] McLaughlin, M.R., Barnett, O.W., Gibson, P.B. \& Burrows, P.M (1984). "Enzyme linked immunosorbent assay of viruses infecting forage legumes, " Phytopathology 74: 965-969.

[21] Betley, M.J. \& Mekalanos. J.J. (1988). "Nucleotide sequence of the type A staphylococcal enterotoxin gene," J. Bacteriol. 170(1): 34-41.

[22] Weir, D., Jones, C., Ammerman, L., Dybdahl, K. \& Tomlinson, S (2007). "Report of a strain of Staphylococcus caprae with the genes for enterotoxin A and enterotoxin-like toxin type P," J. Clin. Microbiol., 45 (10): 3476-3477. 